\title{
DERECHO DEL DEPORTE O DERECHO DEPORTIVO. SU AUTONOMÍA*
}

\author{
SPORTS LAW. ITS AUTONOMY
}

Droit DU SPORT. SON AUTONOMIE

Carlos Clerc ${ }^{* *}$

\section{RESUMEN}

El presente artículo tiene como objetivo fijar mi posición acerca de la Autonomía del Derecho del Deporte o Derecho Deportivo. Para ello, he trabajado con legislación y doctrina tanto argentina como iberoamericana, analizando al Derecho del Deporte desde su gestación embrionaria hasta la actualidad. He compulsado las distintas definiciones de los autores especialistas en la materia, para luego establecer las fuentes de esta nueva rama del Derecho. Hice hincapié en las distintas posiciones de la doctrina en lo referente a la autonomía del Derecho del Deporte, para concluir pretendiendo delinear las características y principios de esta nueva área del derecho, a fin de lograr un abordaje más profundo en su estudio.

PALABRAS CLAVE: Derecho - Deporte - Autonomía

\section{ABSTRACT}

This article has the aim of establishing my stance about the autonomy of Sports Law. I worked with Argentinian and Latin American legislation and legal doctrine, by analyzing Sports Law from its beginning until today. I also reviewed different definitions from authors specialized in the matter in order to set the sources of this new branch of law. Finally, I put special emphasis in the different doctrinaire positions regarding the autonomy of Sports Law, and conclude trying to outline the characteristics and principles of this new branch of law in order to reach a deeper approach in its study.

KEY WORDS: Law - Sport - Autonomy

RÉSUMÉ

Cet article vise à établir ma position sur l'autonomie du Droit du sport. Pour cela, j'ai travaillé avec la loi et la doctrine ibéroaméricain et argentine, en analysant le droit du sport depuis sa création jusqu'à le présente. J'ai comparé les différentes définitions des auteurs dans le domaine, en vue d'établir les sources de cette nouvelle branche du droit. J'ai insisté sur les différentes positions de la doctrine concernant l'autonomie du droit du sport et les caractéristiques et les principes de ce nouveau domaine de la loi, afin de parvenir à une approche plus profonde dans leur étude.

MoTS CLÉs: Droit - Deporte - Autonomie

* El artículo fue aprobado para su publicación el 14 de septiembre de 2012.

** Abogado. Licenciado en Ciencias Jurídicas Universidad de Buenos Aires. Doctor en Derecho Universidad de Buenos Aires. Profesor Titular de Derecho Civil de la Facultad de Derecho de la Universidad Nacional de Lomas de Zamora. Director del Instituto de Derecho Civil de la misma casa de estudios. 


\section{CONCEPTO}

El estudioso brasileño João Lyra FILHo, citado por Valed Perry, escribió: "la institución del deporte no es privativa de un país; impone la creación de un derecho universal, que se basa en principios medios y fines universales, coordinados por leyes propias de ámbito internacional. Tales características confieren al derecho deportivo una importancia que sobre algunos aspectos supera al mayor número de las demás ramas del derecho. El derecho deportivo regula la conformidad de principios internacionales codificados. La disciplina deportiva se entiende como la creación de una pirámide nacida de la suma de los individuos y proyectada al ápice de un comando universal exclusivo. Esto es lo que hace ver la extensión y la profundidad del derecho, cuya realización impone la creación de procesos específicos que preservan la sustancia de la organización y la eficiencia del funcionamiento"1.

Para André Franco MonToro, la cuestión se puede observar desde otra óptica, se puede reconocer el surgimiento de un derecho deportivo ordenado, un derecho deportivo estatal representado por las leyes o normas estatales que disponen sobre la actividad deportiva; un derecho social deportivo constituido por normas reguladoras del deporte elaboradas y aplicadas por las propias organizaciones deportivas ${ }^{2}$.

En una tentativa de establecer una conceptualización más técnica y que sea suficientemente amplia dentro del tema de los deportes y en torno al derecho de los deportes, éste puede ser considerado como: "un conjunto de normas de derecho público y privado, por tanto, estatales y no estatales, que tiene por finalidad principal regular las relaciones de carácter deportivo entre las personas físicas y jurídicas practicantes y de gestión administrativa, estén de manera directa o indirecta envueltas en el segmento deportivo". En síntesis, se puede decir en una proposición más dogmática que se trata de un conjunto de normas de carácter público y privado que regulan la actividad relacionada con los deportes: de parte del Estado por previsión constitucional, leyes decretos, reglamentos, resoluciones, medidas provisorias típicas de la legislación de cada país y por principios normativos de carácter privado concebidos por las instituciones deportivas, principalmente de administración de los deportes, por medio de normas incluidas en sus estatutos que regulan la vida de estas instituciones, y de reglamentos que rigen las competencias deportivas.

El profesor Andrés GiL DOMÍNGUEZ ${ }^{3}$ sostiene: "el derecho del deporte es la disciplina que se encarga de abordar el fenómeno deportivo desde las distintas vertientes

\footnotetext{
${ }^{1}$ Perry, Valed (2002). "Introducción al Derecho Deportivo". Revista de IBDD, San Pablo: Editora OAB. SP., p. 20.

${ }^{2}$ Montoro, Andrés Franco (1997). Introduçao a Ciencia do Direito. San Pablo: Editora Revista dos Tribunais, $24^{\text {a }}$ Edición, p. 553

${ }^{3}$ Gil Domínguez, Andrés (2001). "El derecho al deporte y el derecho del deporte”. Cuadernos de Derecho Deportivo, Buenos Aires: Editorial Ad Hoc, No 1, p. 34.
} 
del derecho, y a la vez posibilita generar intercambios interdisciplinarios que permiten analizar con mayor amplitud y riqueza científica todas las manifestaciones del objeto de estudio: el deporte. El derecho del deporte enfoca los distintos aspectos que presenta el deporte en sus diversas manifestaciones, pero cuidando y respetando la esencia de dicha actividad. Seguido a esto se suma la importancia de los aportes que hacen disciplinas tales como la economía del deporte, la sociología del deporte, la antropología del deporte, la psicología del deporte, la medicina del deporte, etc.”.

Jean Loupe ${ }^{4}$ considera que el derecho deportivo se ha formado sobre tres puntos que considera básicos, dice textualmente: "nosotros tenemos que ver que toda institución genera un derecho disciplinario, un derecho consuetudinario o de costumbres y un derecho estatutario".

Daniel CRESPO5, en Argentina, sostiene que "el ordenamiento jurídico deportivo constituye un sistema normativo especial donde confluyen normas de distinto rango y origen, algunas provenientes del derecho común y otras eminentemente deportivas. La autonomía científica y didáctica de la materia jurídico deportiva y la necesidad de su estudio diferenciado y especializado, también refleja, por ejemplo, los intentos de reforma de la estructura jurídica de los clubes de fútbol de la Argentina". Este autor afirma que el derecho deportivo puede ser considerado una realidad incuestionable, ya sea conviviendo con reglas comunes de otras ramas del derecho como por contener especificidades científicas y de naturaleza didáctica inequívoca, a través del sistema normativo calificado como especial, contando con la necesidad de ser estudiado en forma diferenciada y especializada, y principalmente, por traer en su conceptualización un carácter de evidente autonomía.

En Brasil, Waled PERrY ${ }^{6}$ sostiene que "el derecho deportivo es un complejo de normas y reglas que rigen el deporte en el mundo entero y cuya inobservancia puede acarrear la marginalización total de una asociación del concierto mundial deportivo".

Por lo tanto, las normas son orientadas teniendo como referencia una forma típicamente consuetudinaria, ya sea bajo un aspecto estrictamente técnico inspiradas en un empirismo propio de cada práctica, con reglas propias dictadas al respecto. Dichas reglas son pertinentes a la organización de los eventos y sus disputas, y acaban por ser elaboradas de forma gradual, en buena parte escritas y proyectadas en textos orientativos, y que pasarán a ser adoptadas y respetadas, culminando en los días actuales por ser consideradas y consolidadas como reglas o principios disciplinadores para cada tipo de modalidad de disputa deportiva, naturalmente que relacionada con los problemas e incidentes fácticos propios y los cuestionamientos

\footnotetext{
${ }^{4}$ Loupe, Jean (1930). Les Sports et le droit. París: Librairie Dalloz, p. 31.

${ }^{5}$ Crespo, Daniel y Frega Navia, Ricardo (2006). "La materia jurídico-deportiva. Sujetos, fuentes y principios de interpretación del Derecho deportivo". En: Cuadernos de Derecho Deportivo. No 6/7. Buenos Aires: Editorial Ad Hoc, pp. 19 y ss.

${ }^{6}$ Perry (2002), p. 19.
} 
provenientes de los espectáculos protagonizados por los competidores, ya sea a nivel individual o a nivel colectivo, por ejemplo, el juego de ajedrez, el de tenis, el de un partido de fútbol, el de un partido de volley, etc.

En síntesis, el derecho deportivo puede ser considerado como un conjunto de normas que regulan el deporte en el planeta, cuyas reglas son obligatorias, con la posibilidad que entidades insurgentes que han incumplido esas reglas puedan ser desafiliadas y marginadas del ámbito deportivo mundial, y que corresponda la aplicación de una sanción como reprimenda mayor y que se lo coloque fuera del ámbito de la justicia. En el mismo sentido, Ricardo Frega NavíA ${ }^{7}$ sostiene que "no debe perderse de vista la necesaria referencia al ordenamiento federativo y reglamentario internacional como marco de la incuestionable globalización del derecho deportivo, y la incesante generación de negocios jurídicos que se desarrolló en ese contexto. Cabe analizar ese ordenamiento internacional a la luz de nuestra propia regulación nacional legislativa y reglamentaria”.

El profesor Álvaro Melo Filho ${ }^{8}$, al transcribir un trabajo del profesor Manoel Tubino, sostuvo que hay por lo menos diez categorías distintas de prácticas deportivas:

a) Los deportes olímpicos, como el básquetbol, la natación, el atletismo;

b) Los deportes cuyas principales competencias no son los Juegos Olímpicos: el béisbol, el fútbol, el fútbol americano, el tenis;

c) Los deportes de la naturaleza: caminatas, corridas de orientación, vuelo libre;

d) Los deportes de aventura o desafío donde el riesgo es el componente imprescindible: montañismo, rally del tipo París-Dakar, enduro, bicicross, motociclismo;

e) Los deportes derivados de las artes marciales: yudo, karate;

f) Los deportes interactivos o intelectuales: ajedrez, billar, aeromodelismo;

g) Los deportes de identidad cultural: capoeira, sumo, criquet;

h) Los deportes de expresión corporal: danza deportiva, patinaje, patinaje artístico, aeróbica;

i) Los deportes derivados de otros deportes: futsal, paddle;

j) Los deportes de shopping: patinaje, bowling, kart.

Así como los países elaboran sus propias reglas deportivas, éstas deben observar una sintonía y armonización internacional, permitiendo ser consideradas como esencialmente globales al ser dirigidas a todas las naciones del mundo que deseen participar en certámenes internacionales comunes promovidos, por ejemplo, por la FIFA o el COI.

\footnotetext{
${ }^{7}$ Frega Navia, Ricardo (2005). "Presentación”. Cuadernos de Derecho Deportivo No 2. Buenos Aires: Editorial Ad Hoc, p. 13.

${ }^{8}$ Melo Filho, Álvaro (1998). Lei Pelé. Comentarios a Lei 9615/98. Brasilia: Editora Brasilia Jurídica, $1^{a}$ Edición, pp. 11-12.
} 
Este autor considera que el Derecho Deportivo se configura como una rama jurídica catalizadora de expectativas y experiencias socio-político-educacionaleseconómicas en el plano deportivo compatibilizándolas con un ius singulari que condensa normas de organización, normas de conducta, normas sustantivas y normas procesales a fin de albergar hechos, falencias, especificaciones y relaciones jurídico-deportivas.

Arturo MAJADA" sostiene que: "el derecho deportivo es el conjunto de normas escritas o consuetudinarias que regulan la organización y práctica de los deportes $y$, en general, cuantas cuestiones jurídicas plantea la existencia del deporte como fenómeno de la vida social". En un sentido concordante se expresa CLARÍA ${ }^{10}$ al decir que: "el derecho deportivo se entiende como el conjunto de normas de derecho público y privado, estatal y no estatal, que regula las relaciones entre las personas jurídicas y físicas que directa o indirectamente se vinculan con la actividad deportiva”.

En nuestra opinión, el Derecho Deportivo es una rama del Derecho compuesta por el conjunto de normas que regulan la actividad deportiva en su integridad que tiende a proteger a la persona en dichas prácticas teniendo en mira una finalidad social.

\section{DenOMinACIONES}

Si bien se han utilizado distintas denominaciones para hacer referencia a la rama del Derecho que nos ocupa, debemos destacar que la expresión Derecho Deportivo fue utilizada por primera vez en 1933 en Italia, en una monografía publicada por Cesarini SFORZA, a propósito de la revisión judicial de ciertas sanciones disciplinarias del Jockey Club de Italia. Invocaba el institucionalismo de Santi Romano para señalar que toda organización o institución se confunde o identifica con un ordenamiento jurídico autónomo y en consecuencia, la comunidad deportiva generaba su propio derecho, sus propias relaciones jurídicas, bajo formas y principios diferentes a los estatales y, desde luego, autosuficientes. Con posterioridad, se han empleado distintas expresiones para denominar a esta área: Derecho Deportivo, Derecho del Deporte, legislación deportiva; en Brasil se lo conoce como Direito do Desporto, Sports Law en los países del Common Law, Sportrcht en Alemania, Droit du Sport en Francia, Diritto Sportivo en Italia. En nuestro trabajo utilizamos indistintamente las expresiones Derecho del Deporte o Derecho Deportivo como equivalentes.

\footnotetext{
${ }^{9}$ MajADA, Arturo (1948). Naturaleza jurídica del contrato deportivo: concepto-legislación. Barcelona: Editorial Bosch, pp. 5 y ss.

${ }^{10}$ Clariá, José Octavio (2005). "La actualidad del Derecho Deportivo". Biblioteca jurídica on line "Gustavo Bossert", 5 de julio de 2005. Disponible en: <http://www. eldial.com>.
} 


\section{Derecho del Deporte. Sus particularidades}

En las últimas décadas del siglo pasado y comienzos de este siglo hemos visto cómo se han consolidado nuevas ramas del Derecho. Así, desde 1973, comenzamos a hablar y constituir las bases del Derecho Ambiental; un poco más adelante en el tiempo separamos el derecho de daños del de las obligaciones. En ese mismo sentido se forjó el derecho de los consumidores y también el derecho de las nuevas tecnologías comenzó a ser materia de estudio independiente. En ese contexto creemos y ahora podemos hablar, sin temor a equivocarnos, de una nueva rama del Derecho que es el Derecho del Deporte o Derecho Deportivo, del cual pasaremos a considerar algunas de sus particularidades.

Sin dejar de tener en cuenta algunas críticas que ponen en duda la existencia de esta nueva rama, como las que en su momento efectuaran Juan Ángel CONFALONIERI, en Argentina o Monge GiL, en España, consideramos que es didáctico y prácticamente correcto referirnos a un Derecho del Deporte o Derecho Deportivo.

$\mathrm{Al}$ respecto de las especializaciones que se forman dentro del ámbito del derecho, Álvaro Melo FilHo ${ }^{11}$ sostuvo que "las especializaciones en el campo jurídico constatadas a partir de nuevas ramas del Derecho por su carácter de vanguardia en la marcha de la ciencia jurídica ejercen una profunda influencia sobre sus aspectos clásicos obligando a los juristas a alterar conceptos cristalizados por los tiempos, pero ya enteramente vacíos de sentido y de contemporaneidad con la época actual. No obstante, no debe el especialista de cada rama perder el sentimiento de unidad de derecho como un todo, pues debe tener una concepción general de los problemas en su totalidad para que pueda colocar bien en su campo personal la exacta posición de la sistemática que le compete, pero sin comprometer el objeto y los fines propios de su campo particular, porque trabajando en el desenvolvimiento de éste, estará colaborando con el progreso de todo el conjunto”.

Por otro lado, existen otros estudiosos que entienden al Derecho del Deporte como un gran marco de retazos formado por todo el Derecho regularmente constituido, con normas utilizadas que surgen de otras ramas clásicas del Derecho, o sea, del área pública con reglas que son originarias del derecho administrativo bajo la égida del control público sobre la actividad; del ámbito tributario que se ocupa de la tributación que incide sobre la actividad; en el derecho del trabajo en la relación de empleo, subordinada de carácter laboral preponderantemente entre el atleta y la asociación deportiva; en el área de las reglas privadas, a través del Derecho Civil, del Derecho Comercial-empresarial, de los derechos de naturaleza privada fijados por contratos celebrados inclusive por intermedio de sociedades, estatutos de asociaciones, textos y códigos conteniendo reglas disciplinarias, de los derechos relacionados con la imagen y la arena, todos los actos jurídicos típicos del deporte formal y de rendimiento.

\footnotetext{
${ }^{11}$ Melo Filho (1998).
} 
En este orden de ideas, Emilio Nova, citado por João Lyra FILHO ${ }^{12}$ dice: "el derecho deportivo es un derecho de carácter voluntario y autónomo, atendida la circunstancia de que los propios aficionados o profesionales se someten y acatan las reglas del deporte que practican o que ellos mismos en sus propias organizaciones elaboran".

Jean Loupe ${ }^{13}$ dice que el derecho deportivo puede ser interpretado a voluntad pero es indiscutible su existencia, y agrega que el derecho deportivo está contenido en los estatutos y reglamentos de la institución y que en varios países es reconocido por el Estado.

João LYRA FILHO ${ }^{14}$, tomando como referentes a Arturo MAJADA y a Emilio Nova, dice textualmente: "el derecho del deporte es una rama jurídica de novísima creación de carácter autónomo"; en sentido estricto, el derecho deportivo es la suma de las leyes internas creadas y formalizadas dentro y por inspiración del deporte.

\section{Fuentes del Derecho}

Según Guillermo BordA ${ }^{15}$, la expresión fuentes del derecho suele usarse en tres sentidos distintos. Desde un punto de vista, que podemos llamar filosófico, significa la esencia suprema de la idea del Derecho; en este sentido, el Preámbulo de la Constitución argentina invoca la protección de Dios, fuente de toda razón y justicia. Desde otro punto de vista, que puede calificarse de histórico, fuentes del derecho alude a los antecedentes patrios o extranjeros que han podido servir de base a un determinado orden jurídico: es así que se afirma que las fuentes de nuestro Código Civil han sido el derecho romano, la legislación española, el Código Napoleón, etc. Finalmente, la expresión fuentes del derecho se aplica a las normas o preceptos del Derecho positivo del cual nacen derechos y obligaciones para las personas. Es en este sentido que usaremos la palabra fuente. Para CifUENTES ${ }^{16}$, "se llaman fuentes del derecho los modos como se manifiesta el derecho; los medios a través de los cuales se exterioriza, o se presenta revelando su contenido y sus mandatos". Las fuentes se clasifican en formales y materiales, las formales tienen obligatoriedad debido a su fuerza extrínseca, relacionada con el órgano que las creó. Tienen autoridad por sí mismas, dejando de lado la validez justa o racional de su contenido. Son fuentes directas. Las fuentes materiales no tienen autoridad propia, sino que, dando cuenta de la verdad de sus postulados y la justicia o conveniencia

\footnotetext{
${ }^{12}$ Lyra Filho, João (1952). Introduçao ao Direito Desportivo. Río de Janeiro: Irmaos Pongetti Editores, pp. $14,15,28$ y 29.

${ }^{13}$ LOUPE (1930).

${ }^{14}$ LyRa FilHo (1952).

15 Borda, Guillermo A. (1985). Manual de Derecho Civil. Parte General. Buenos Aires: Abeledo Perrot, $12^{\text {a }}$ Edición, pp. 36 y ss.

16 Cifuentes, Santos (1988). Elementos de Derecho Civil. Parte General. Buenos Aires: Editorial Astrea, pp. 4 y ss.
} 
de su solución, persuaden y hacen que los órganos con poder las adopten para aplicarlas. Son fuentes indirectas, pues no valen por sí mismas sino por su valor intrínseco que induce a los órganos a darles eficacia y autoridad.

Las fuentes clásicas son la ley, la costumbre, la jurisprudencia y la doctrina. Actualmente se reconoce el valor de fuente a los Principios Generales del Derecho, a la equidad, a los convenios colectivos de trabajo, etc.

Son fuentes formales:

1. La ley en sentido amplio o material.

2. La costumbre secundum legem.

3. La costumbre praeter legem.

4. La jurisprudencia plenaria o de casación.

Son fuentes materiales:

1. La doctrina de los autores.

2. La jurisprudencia no obligatoria.

3. La costumbre contra legem.

En materia de Derecho del Deporte quedan comprendidos dentro del concepto de fuente:

1. Las Constituciones Políticas.

2. Las leyes emanadas del Poder Legislativo o leyes strictu sensu.

3. Los reglamentos emanados del Poder Ejecutivo con el fin de regular en detalle las leyes.

4. Las ordenanzas municipales.

5. La costumbre.

6. La jurisprudencia.

7. La doctrina.

A continuación analizaremos las fuentes del Derecho del Deporte más importantes.

\subsection{La ley}

Dentro de estas fuentes es innegable que la ley es la principal fuente formal del Derecho del Deporte. Al no existir un ordenamiento jurídico deportivo integral, es imprescindible acudir a las leyes generales para poder dar solución a los casos que se planteen. Lógicamente que las leyes especiales del Derecho del Deporte constituyen una fuente fundamental, a las que habrá que recurrir prioritariamente para la resolución de los eventuales conflictos que pudieran plantearse por la actividad deportiva.

\subsection{Los reglamentos}

Los reglamentos nacionales e internacionales emanados de las federaciones y asociaciones deportivas constituyen una fuente de singular importancia en la materia, ya que ellos no se limitan a las normas de la competencia deportiva, sino que también legislan cuestiones que se refieren al ámbito laboral o comercial. 


\subsection{La costumbre}

Independientemente de que la práctica deportiva sea o no competitiva, ésta es llevada a cabo bajo ciertas reglas que son de aceptación casi universal, siendo autosuficientes tanto para la práctica privada como para la competencia ordenada u organizada por las federaciones nacionales. Estas reglas de juego son las que nos permiten decir quién gana y quién pierde, han sido adquiridas por el transcurso del tiempo, de modo que el carácter consuetudinario configura un matiz importante en la normatividad deportiva. Por lo tanto, la costumbre en las relaciones deportivas es fuente de derecho en el entendido que sus usos y prácticas deben ser tenidas en cuenta al momento de premiar al ganador, resolver un conflicto de intereses, más aún tratándose de un derecho nuevo, en surgimiento, que debe ir alimentándose del quehacer y de las vivencias diarias de sus actores.

LYRA ${ }^{17}$ sostiene que "la costumbre en el derecho deportivo es un derecho creado por las masas, a diferencia de la ley, que es un derecho creado por las elites". Continúa diciendo: "En el Derecho Deportivo la costumbre ha jugado un papel importante en razón que está en proceso de normatización. En este orden de ideas a falta de norma legal expresa puede aceptarse la aplicación de la costumbre, como ha venido sucediendo en materia deportiva. Los profesionales del derecho, magistrados, árbitros tienen que descender al submundo de las costumbres populares y de la convivencia de los pueblos, cuya capacidad creadora es uno de los más bellos ejemplos".

\subsection{La jurisprudencia}

Las decisiones judiciales que pueden emanar de diversos tribunales nacionales, de otros países, las de los Estados de la Unión Europea o también de organismos jurisdiccionales federativos adquieren en este estadio del Derecho del Deporte una fundamental trascendencia, ya que la evolución de esta rama está ligada a la labor de dichos tribunales que deben dar solución a los conflictos que se producen entre los distintos actores. Por lo tanto, la jurisprudencia también es una fuente del Derecho Deportivo.

\subsection{La doctrina}

Si bien sus opiniones no son vinculantes, no obstante la labor de los autores suele ser citada en las sentencias y, en algunos casos, en los fundamentos de las mismas leyes. En los últimos años, el Derecho del Deporte se ha nutrido de obras especializadas en el tema, como así también de artículos sobre temas puntuales de gran interés para el operador jurídico.

${ }^{17}$ LYRA FilHo (1952). 
Las Universidades no han sido ajenas a este proceso evolutivo. La Facultad de Derecho de la Universidad Nacional de Lomas de Zamora organizó en septiembre de 2007 las XXI Jornadas Nacionales de Derecho Civil, reunión científica de máxima trascendencia en Argentina, en cuya comisión No 10, denominada Derecho Privado Comparado, se trató el tema: Derecho Deportivo. Fue la misma Facultad de Derecho de la Universidad Nacional de Lomas de Zamora la que creó dentro de sus Carreras de Posgrado la de Abogado Especialista en Derecho Deportivo, cuyo Director es el Dr. Pablo Barbieri y cuenta con el Dr. Daniel Crespo como Presidente de su Consejo Académico.

\section{Derecho del Deporte. Su autonomía}

La palabra autonomía deriva del vocablo originario de la lengua griega: autos, que significa igual a sí mismo, y nomos, que significa ley. Se puede interpretar como una independencia, un acto de gobernar por sus propias reglas; observando que la autonomía deportiva, en la hipótesis, equivaldría a una independencia administrativa, a la facultad reconocida por el Estado declarando su obligatoriedad y para regirse por las propias leyes y particularidades referidas a su actividad.

Sobre la reconocida autonomía aplicable al Derecho del Deporte es importante la posición adoptada por REAL FERRER ${ }^{18}$, quien considera que "para que pueda predicarse la autonomía de una disciplina jurídica, deben concurrir las siguientes circunstancias:

a) un ámbito de la realidad bien acotado (autonomía objetiva),

b) un conjunto de principios propios (autonomía conceptual o dogmática),

c) la existencia de un conjunto de normas y relaciones homogéneas".

Los tres elementos están presentes en el Derecho del Deporte. Un ámbito de la realidad bien acotado significa que existe un conjunto de relaciones sociales que por su naturaleza, sus particularidades y para conseguir un determinado grado de desarrollo necesitan y demandan un ordenamiento jurídico propio: el deporte como fenómeno social lo generó espontáneamente. El ordenamiento deportivo supone un grupo de reglas que implica un conjunto sistemático de normas, y a la vez, expresa cierta homogeneidad en las relaciones y las normas que lo componen.

Sobre el contenido de esta homogeneidad, que se expresa a través de las propias normas, GiL DomínGUEZ 19 sostiene que: "la homogeneidad se evidencia por cuanto ambas pretenden el pleno funcionamiento y mejora del deporte, y porque regulan relaciones que se dirigen a un mismo fin". En cuanto a los principios, continúa diciendo, nosotros creemos, de manera enunciativa, que en el Derecho del Deporte son los siguientes:

${ }^{18}$ Real Ferrer, Gabriel (1991). Derecho Público del Deporte. Madrid: Civitas.

${ }^{19}$ Gil Domínguez (2001). 
a) Principio de subordinación al orden jurídico constitucional,

b) Principio de reconocimiento, protección y promoción del deporte como derecho colectivo,

c) Principio de promoción estatal,

d) Principio de no discriminación,

e) Principio de tutela jurídica eficaz, necesaria y proporcional,

f) Principio de acceso a la jurisdicción,

g) Principio de especialidad.

Según este mismo autor, a nivel mundial, el deporte se ha visto dotado, en estos últimos cien años, de una organización perfectamente entramada que dio origen ex novo a un ordenamiento jurídico originario y extra estatal que regula imperativamente un significativo número de relaciones jurídicas desarrolladas en torno a las prácticas deportivas. A mayor abundamiento, GIL DomíngUEZ continúa diciendo: "este ordenamiento es originario, por cuanto evidentemente no existe otro superior del que tome su legitimidad y en el que confíe para imponer su coacción. Su legitimidad le viene dada por su emergencia voluntaria y convencional, y por su sostenimiento actual basado en la existencia de 'un vínculo deportivo' que une a los individuos y organizaciones que se adscriben al movimiento deportivo mundial. La naturaleza de su coacción hay que buscarla en la posición monopolística que ese otorgamiento otorga a un 'poder deportivo' que proyecta su imperio sobre la casi totalidad de las relaciones"; toda la temática en estudio tiene su apoyo necesariamente en la existencia de un vínculo de naturaleza deportiva que compone la relación jurídica con características netamente especiales. Afirma que dicho ordenamiento es internacional en el sentido de que su ámbito territorial se extiende por todo el mundo. Pero esa internacionalidad es extra estatal, por cuanto los Estados no son sujetos de su ordenamiento, sino tan sólo unidades territoriales sobre las que se asientan y extienden su jurisdicción las instituciones deportivas de alcance nacional. El ordenamiento jurídico deportivo internacional es un ordenamiento complejo del que penden los distintos ordenamientos internacionales configuradores de los diversos deportes. Generalmente, cada deporte se estructura internacionalmente en una organización única en cuyo vértice se encuentra la federación internacional correspondiente. La suma de esas organizaciones vertebra es la llamada trama federativa.

En cuanto a la sistematización y estructuración de los deportes, GiL DomínGUEZ considera que: "la organización deportiva viene, pues, constituida por dos estructuras paralelas pero estrechamente interrelacionadas: la trama olímpica y la federativa. Las federaciones internacionales (agrupaciones privadas con competencias internacionales que dirigen el deporte a nivel mundial y que asumen la responsabilidad de su organización y gestión) ejercen funciones normativas y disciplinarias de alcance mundial, y de carácter sectorial vinculado a las federaciones nacionales respectivas. A su vez, las nacionales y territoriales ejercen las mismas funciones en sus ámbitos zonales. 
El deporte federativo, en los distintos escalones de su estructura, tiene como misión el fomento de un determinado deporte y realiza, esencialmente, las funciones relativas al establecimiento de las reglas técnicas y de competición de cada deporte. Así como su vigilancia, y la organización de campeonatos en los distintos niveles cualitativos y cuantitativos, es decir, por categorías y por territorios. Las federaciones, cada una en su ámbito geográfico, representan un determinado deporte en un determinado territorio, por lo que se puede predicar que en su organización rige el principio de la especialidad. La estructura olímpica, en cambio, tiene como función la de preservar "el ideal olímpico" como un instrumento de mejora de los individuos y de entendimiento entre los pueblos, cuya materialización es la celebración de los Juegos Olímpicos. El Comité Olímpico Internacional (COI) dirige y controla todas las cuestiones relativas a la aplicación de las reglas olímpicas y a la organización de los juegos, sin intervenir en la formulación de reglas técnicas de cada deporte. Los comités nacionales, constituidos según las reglas del internacional, tienen la responsabilidad de organizar la participación en los juegos. Por ello, mientras el COI representa al movimiento olímpico y los comités nacionales a ese mismo movimiento, pero en sus respectivas naciones, las federaciones representan a los distintos deportes. El referido autor concluye que: "El ordenamiento jurídico internacional queda a la puerta del Estado, y si proyecta su influjo sobre el derecho interno, lo hace en su calidad de exteriorización de un movimiento social pero ausente de juridicidad. A partir de este punto, el ordenamiento deportivo interno será lo que el Estado quiera que sea. Aunque permita al ordenamiento deportivo ocupar los 'espacios libres' de su propio ordenamiento en aquellas cuestiones que estime irrelevantes, aquél será recibido, modulado e integrado en éste de tal suerte que pasará a formar parte del mismo ordenamiento sectorial, y por tanto, subordinado al general. El ordenamiento deportivo no se puede abstraer de las normas del Estado. Uno y otro forman una unidad, orgánica, dogmática y teleológicamente considerada. Se perciben dos esferas suficientemente coherentes para otorgar al derecho deportivo el reconocimiento de una rama científica autónoma dentro del Derecho. En la primera se ubica el ordenamiento jurídico internacional, que si bien tiene una naturaleza privada por emanar de organizaciones 'no gubernamentales', desde luego concita todas las características de un ordenamiento jurídico originario. En la segunda, nos encontramos con una serie de ordenamientos deportivos internos, conectados con su respectivo orden jurídico estatal que está integrado por una serie de normas públicas y privadas que tienen como denominador común regular las relaciones jurídico-deportivas".

Pablo BARBIERI ${ }^{20}$ reconoce implícitamente la autonomía de esta rama cuando sostiene que: "El Derecho Deportivo es la rama del Derecho que se ocupa del estudio de las relaciones jurídicas derivadas del deporte"; de este concepto se pueden extraer los siguientes contenidos de la disciplina.

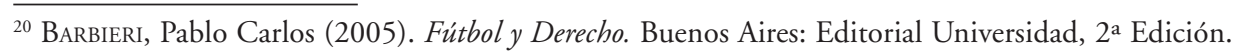


a. Relaciones jurídicas entre los deportistas y los clubes, federaciones o asociaciones.

b. Relaciones jurídicas entre los clubes y las asociaciones, federaciones y confederaciones que los nuclean o agrupan.

c. Relaciones jurídicas entre asociaciones, federaciones y confederaciones nacionales y aquellas supranacionales que los agrupan.

d. Régimen jurídico de los deportistas amateurs y profesionales.

e. Reglamentos de la práctica de los distintos deportes.

f. Sanciones disciplinarias y recursos procesales contra las mismas.

g. Daños y perjuicios derivados de la práctica del deporte.

h. Daños y perjuicios derivados del espectáculo deportivo.

i. Relaciones contractuales generadas en torno al deporte, como por ejemplo, el contrato de espectáculo deportivo, esponsoreo, publicidad, merchandising.

j. Responsabilidades civiles y penales derivadas de delitos y cuasi delitos cometidos en espectáculos deportivos.

k. Derecho de imagen del deportista.

1. Legislación nacional e internacional. vencia.

$\mathrm{m}$. Régimen jurídico de las entidades deportivas y tratamiento de su insol-

La enumeración precedente es de carácter enunciativo, teniendo en cuenta la amplitud de relaciones jurídicas comprendidas en el estudio de la disciplina y la constante incorporación de nuevas circunstancias como ha ocurrido en Argentina con los contratos de gerenciamiento o el fideicomiso para entidades deportivas en dificultades".

Ya adelantamos que parte de la doctrina niega el carácter de autónomo del Derecho del Deporte, basada fundamentalmente en que carece de conceptos y categorías propias y también de principios que le sean propios, puesto que la regulación del deporte se nutre de las distintas ramas del derecho como lo son, por ejemplo, el Derecho Civil, el Derecho Comercial, el Derecho Laboral y el Derecho Administrativo.

No debemos dejar de hacer mención a una tercera posición, que podríamos denominar ecléctica, que en algún momento compartimos, cuando unos años atrás decíamos comentando la posición negativa de MONGE GIL: "En nuestra opinión, la dispersión de la que habla este autor constituye la constatación de la realidad del presente, lo cual no obsta para que la sistematización de las reglas jurídicas que tienen por objeto principal la ordenación de las actividades deportivas, aparezca como una insoslayable necesidad para el estudio de este sector de la realidad dotado de particularidades y caracteres específicos. Por tanto, consideramos que se está generando una nueva rama del derecho con principios y fuentes propios que nos permiten vislumbrar su pronta autonomía"21.

${ }^{21}$ ClerC, Carlos Mario (2007). "Hacia un derecho deportivo". Revista Jurídica Facultad de Derecho Universidad Nacional de Lomas de Zamora, Año 3, No 5, pp. 35 y ss. 
En el mismo sentido, Juan BarRachina, sostuvo que "el Derecho Deportivo pugna por ser autónomo en el ordenamiento jurídico a pesar de estar integrado por normas que proceden del Derecho Civil, del Derecho Administrativo y del Derecho Laboral. Con el paso del tiempo y de las aportaciones tanto legislativas como jurisprudenciales, no cabe duda de que este conjunto normativo especial adquirirá una personalidad propia, con sus propios principios generales, diferenciados del resto del ordenamiento jurídico" 22 .

\section{La legislación del Deporte en Argentina}

En Argentina podemos encontrar una copiosa legislación vinculada directamente con la actividad deportiva. Sin entrar en el análisis de ellas, podemos mencionar:

a. La Constitución de la Ciudad Autónoma de Buenos Aires, cuyo artículo 33 promueve la práctica del deporte y el sostenimiento de centros deportivos gratuitos.

b. La Ley Nacional del Deporte No 20.655 y sus resoluciones reglamentarias.

c. La Resolución No 154/96 de la Secretaría de Deportes, que crea el Registro Nacional de Instituciones Deportivas.

d. La Ley No 20.160, denominada Estatuto del Futbolista Profesional.

e. Convenio Colectivo de Trabajo 430/75.

f. La Ley No 24.189 modificada por la Ley No 25.387, Ley Antidoping.

g. La Ley No 23.184 modificada por la Ley No 24.192, represión penal y contravencional para la prevención de la violencia en los espectáculos deportivos.

h. La Ley No 25.284, régimen de administración de entidades deportivas con dificultades.

i. Convención Colectiva de Trabajo No 170/75 Directores Técnicos del Fútbol argentino.

Existen también normas de los Códigos Civil, Comercial, Penal, normas laborales, normas fiscales y normas de Derecho Administrativo que son aplicables a las relaciones jurídicas deportivas. Por ejemplo, la aplicación de las normas del Código Civil referidas a la existencia y constitución de personas jurídicas o a la capacidad de los menores de edad para celebrar contratos. Existen, finalmente, las normas que están contenidas en los Estatutos y Reglamentos de cada una de las asociaciones y federaciones nacionales e internacionales que organizan cada deporte, y asimismo, las normas estatutarias de cada club o asociación. Tales serían, por ejemplo, las normas que surgen de los estatutos y reglamentos de la Federación Internacional de Fútbol Asociado (FIFA), la Asociación del Fútbol Argentino (AFA), la Unión

${ }^{22}$ Barrachina Juan, Eduardo (2001). Derecho del Deporte. Barcelona: Editorial PPU. 
Argentina de Rugby (UAR) o la Unión de Rugby de Buenos Aires (URBA) o demás asociaciones provinciales de rugby o de cualquiera de los demás deportes.

\section{CONCLUSiOnes}

Pensamos que ese embrionario Derecho del Deporte que comenzamos a estudiar hace más de una década ha alcanzado un grado de desarrollo tal que en la actualidad no puede dudarse de la autonomía de esta nueva rama del Derecho. Sus notas diferenciales, a nuestro entender son:

a) Está conformado por un conjunto de normas que regulan la actividad deportiva, sus consecuencias y la trascendencia social de dicha actividad.

b) Reconoce fuentes propias: las leyes deportivas, la jurisprudencia nacional e internacional, la costumbre deportiva y la doctrina.

c) Presenta una dicotomía público-privada en la generación de sus normas. Algunas provienen de la actividad legislativa estatal y otras se originan en instituciones privadas que reglamentan el desarrollo del deporte. Por ello no podemos clasificarlo ni dentro del derecho público ni dentro del derecho privado, puede decirse que es un derecho de naturaleza mixta.

d) La relación jurídica deportiva se conforma con sujetos que son propios de esta rama del derecho, así, son sujetos del Derecho Deportivo: los deportistas, los espectadores, los dirigentes de los clubes, los agentes, los patrocinadores, los directores técnicos, los preparadores físicos, los árbitros, los jueces, los organizadores de espectáculos deportivos, los clubes, las federaciones, las confederaciones, las ligas, etc. Cada uno de ellos con su marco de acción regulado por las normas son los que permiten la concreción de la actividad deportiva.

e) Es un derecho cuya característica más visible es su dinamismo, por las continuas normas que se van sucediendo en el tiempo y que van sistematizando este nuevo ordenamiento.

f) Es imperativo, puesto que sus normas por relacionarse con derechos fundamentales como la salud, la dignidad y la vida de las personas no pueden dejarse en manos de la voluntad de los particulares.

g) La circunstancia de que el Derecho del Deporte toma normas y principios de otras ramas del derecho no puede descalificar la autonomía de esta nueva disciplina normativa, por el contrario, reafirma su independencia, puesto que ninguna de las ramas tradicionales en la que se divide el derecho han podido dar respuesta a los conflictos planteados que, por su complejidad y diversidad, genera la actividad deportiva.

h) El Derecho del Deporte ha creado una terminología propia y puntualmente definida para identificar a todos los operadores de la actividad. 


\section{BiBLIOGRAFÍA CITADA}

Barbieri, Pablo Carlos (2005). Fútbol y Derecho. Buenos Aires: Editorial Universidad, 2a Edición.

BARBIERI, Pablo Carlos (2004). Representación de deportistas. Buenos Aires: Editorial Universidad, $1^{\text {a }}$ Edición.

Barbieri, Pablo Carlos (2011). Régimen jurídico, administración y gestión de los clubes deportivos. Buenos Aires: Editorial Ad Hoc, $1^{\text {a }}$ Edición.

Barrachina Juan, Eduardo (2001). Derecho del Deporte. Barcelona: Editorial PPU.

Barreu, Jean Jacques y Morne, Jean Jacques (1991). Epistemología y Antropología del deporte. Madrid: Alianza Editorial.

Borda, Guillermo A. (1985). Manual de Derecho Civil. Parte General. Buenos Aires: Abeledo Perrot, 12a Edición.

BuIza, Alfredo Allué (2004). Introducción al derecho del deporte. CASADO, Julián Espartero (Coord.), Madrid: Editorial Dykinson S.L.

Cagigal, José María (1975). El deporte en la sociedad actual. Madrid: Editorial Prensa Española y Magisterio Español, Colección RTVE.

Cazorla Prieto, Luis María (1992). Derecho del deporte. Madrid: Editorial Tecnos.

Cifuentes, Santos (1988). Elementos de Derecho Civil. Parte General. Buenos Aires: Editorial Astrea.

Clariá, José Octavio (2005). "La actualidad del Derecho Deportivo". Biblioteca jurídica on line "Gustavo Bossert", 5 de julio de 2005. Disponible en: <http:// www. eldial.com>.

Clerc, Carlos Mario (2007). "Hacia un derecho deportivo". Revista Jurídica Facultad de Derecho Universidad Nacional de Lomas de Zamora, Año 3, No 5.

Crespo, Daniel y Frega Navia, Ricardo (2005). Cuadernos de Derecho Deportivo. No 2. Buenos Aires: Editorial Ad Hoc.

Crespo, Daniel y Frega Navia, Ricardo (2006). "La materia jurídico-deportiva. Sujetos, fuentes y principios de interpretación del Derecho deportivo". En: Cuadernos de Derecho Deportivo. No 6/7. Buenos Aires: Editorial Ad Hoc.

Gil Domínguez, Andrés (2001). "El derecho al deporte y el derecho del deporte". Cuadernos de Derecho Deportivo, Buenos Aires: Editorial Ad Hoc, No 1.

Lyra Filho, João (1952). Introduçao ao Direito Desportivo. Río de Janeiro: Irmaos Pongetti Editores.

Loupe, Jean (1930). Les Sports et le droit. Paris: Librairie Dalloz.

Magnane, George (1966). Sociologie du sport. Paris: Éditions Gallimard.

MajadA, Arturo (1948). Naturaleza jurídica del contrato deportivo: concepto-legislación. Barcelona: Editorial Bosch. 
Melo Filho, Álvaro (1986). Derecho Deportivo actual. Río de Janeiro: Forense. Melo Filho, Álvaro (1998). Lei Pelé. Comentarios a Lei 9615/98. Brasilia: Editora Brasilia Jurídica, $1^{\text {a }}$ Edición.

Montoro, Andrés Franco (1997). Introduçao a Ciencia do Direito. San Pablo: Editora Revista dos Tribunais, 24a Edición.

Perry, Valed (2002). "Introducción al Derecho Deportivo". Revista de IBDD, San Pablo: Editora OAB.SP.

Real Ferrer, Gabriel (1991). Derecho Público del Deporte. Madrid: Civitas. Thomas, R. (1988). Sociología del deporte. Barcelona: Ediciones Bellaterra. VIANA, Eduardo (2004). "La realidad deportiva brasileña y el derecho deportivo". Revista IBDD.SP. 